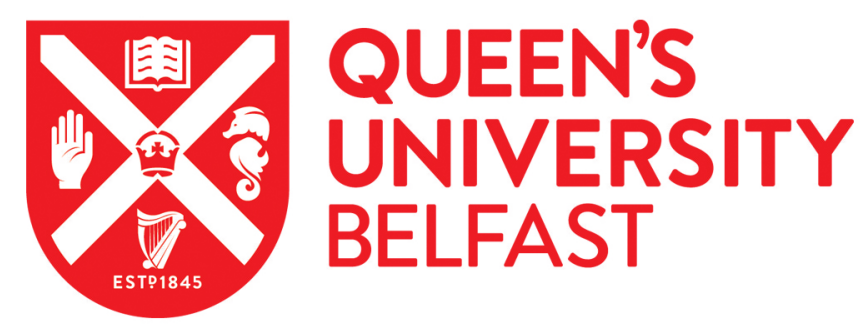

\title{
Using the Quality Circle approach to empower disadvantaged youth in addressing cyberbullying: An exploration across five European countries
}

Hamilton, J., Purdy, N., Willems, R. A., Smith, P. K., Culbert, C., Brighi, A., Fiedler, N., Guarini, A., Mameli, C., Menin, D., Scheithauer, H., \& Völlink, T. (2020). Using the Quality Circle approach to empower disadvantaged youth in addressing cyberbullying: An exploration across five European countries. Pastoral Care in Education, 38(3), 254-272. https://doi.org/10.1080/02643944.2020.1788127

Published in:

Pastoral Care in Education

Document Version:

Peer reviewed version

Queen's University Belfast - Research Portal:

Link to publication record in Queen's University Belfast Research Portal

Publisher rights

Copyright 2020 T \& F. This work is made available online in accordance with the publisher's policies. Please refer to any applicable terms of use of the publisher.

\section{General rights}

Copyright for the publications made accessible via the Queen's University Belfast Research Portal is retained by the author(s) and / or other copyright owners and it is a condition of accessing these publications that users recognise and abide by the legal requirements associated with these rights.

\section{Take down policy}

The Research Portal is Queen's institutional repository that provides access to Queen's research output. Every effort has been made to ensure that content in the Research Portal does not infringe any person's rights, or applicable UK laws. If you discover content in the

Research Portal that you believe breaches copyright or violates any law, please contact openaccess@qub.ac.uk. 


\section{Using the Quality Circle approach to empower disadvantaged youth in addressing cyberbullying: An exploration across five European countries}

Mrs. Jayne Hamilton - Queen's University, Belfast; jayne.hamilton@qub.ac.uk; https://orcid.org/0000-0002-3961-6545; @JayneHamNI (corresponding author)

Dr. Noel Purdy - Stranmillis University College; n.purdy@stran.ac.uk; https://orcid.org/0000-00026180-9669; @NoelPurdy

Dr. Roy A. Willems - Open University of the Netherlands; roy.willems@ou.nl; https://orcid.org/00000002-5775-3367; @RoyAWillems

Prof. Peter K. Smith - Goldsmiths: University of London; p.smith@gold.ac.uk; https://orcid.org/0000$\underline{0002-5010-5359}$

Mrs. Catherine Culbert - Goldsmiths: University of London; catherine.culbert@gold.ac.uk

Prof. Antonella Brighi - Free University of Bozen-Bolzano; antonella.brighi@unibz.it;

https://orcid.org/0000-0002-7536-8569

Dr. Nora Fiedler - Freie Universität: Berlin: nora.fiedler@fu-berlin.de

Prof. Annalisa Guarini - University of Bologna; annalisa.guarini@ unibo.it; https://orcid.org/0000$\underline{0002-3739-2162}$

Dr. Consuelo Mameli - University of Bologna; consuelo.mameli@ unibo.it; https://orcid.org/0000$\underline{0001-5701-0902}$

Dr. Damiano Menin - Free University of Bozen-Bolzano; damiano.menin@unibz.it

Prof. Herbert Scheithauer - Freie Universität: Berlin; herbert.scheithauer@fu-berlin.de

Dr. Trijntje Völlink - Open University of the Netherlands; trijntje.vollink@ou.nl;

https://orcid.org/0000-0001-6531-3399 


\begin{abstract}
Digital communication technologies play an important role in the social development of young people, but can create vulnerabilities to cyberbullying and other negative online experiences. The Blurred Lives project aimed to tackle cyberbullying innovatively using a co-participatory approach, collaborating with 14-16-year olds living in areas of socioeconomic disadvantage in five European countries. In phase one, 2,658 teenagers were surveyed on their internet use and any unpleasant online experiences. This data informed the second phase where the participating countries worked together with 237 adolescents across 10 schools with adult facilitators to create original anti-cyberbullying resources for teachers, parents/carers, peers, and social media providers using the Quality Circle approach. This methodology adopts an ethos of working together to solve a problem in small, peer-led groups. Each group was tasked with creating a resource for one of the target audience groups. The final resources comprise a rich variety of different formats including videos, comic strips, a board game, leaflets, posters, and newsletters. The pupil feedback highlights, for most but not all participants, an increased knowledge of cyberbullying and e-safety skills, as well as enhanced problem-solving skills, levels of confidence, and group work skills. Several operational challenges are also discussed, including the importance of school-level support, planning, staffing, and finding an appropriate balance between facilitator support and pupil agency.
\end{abstract}

Keywords: cyberbullying, co-participation, quality circles, social disadvantage, adolescents 


\section{Introduction}

Although rapid advances in online technology and connectivity have brought many benefits to young people (Costabile \& Spears, 2012), there is increasing concern for young people regarding their use of and potential dangers arising from unlimited access to the internet (Låftman et al., 2013; Livingstone \& Helsper, 2010). A troubling phenomenon that has developed recently in schools is cyberbullying; it displays similar characteristics to traditional bullying where there is repeated, aggressive behaviour towards a victim who cannot easily defend themselves (Olweus, 1994), using methods of electronic communication (Smith et al., 2008; Schultze-Krumbholz \& Scheithauer, 2015). The range of harmful consequences of cyberbullying to victims has been widely documented (Cowie, 2013; John et al., 2018; Ditch the Label, 2019). However, there is continuing debate about how appropriate it is to carry over the definition of traditional bullying to cyberbullying (Kofoed \& Staksrud, 2018): some researchers prefer to use the concept of cyber-aggression more generally, although much research continues to use the term cyberbullying, as indicated in the major review by Kowalski et al. (2014). In the Blurred Lives project, this issue was initially circumvented by asking pupils about 'nasty experiences on the internet', aiming to provide a broader space to report forms of cyber-aggression and cyber-bullying.

\section{Co-participation in cyberbullying research}

Schubotz (2020) has argued that children and young people often remain excluded from decision making about issues affecting their lives, despite the legal framework provided by the United Nations Convention on the Rights of the Child [UNCRC] (UNICEF, 1989). For instance, Article 12 of the UNCRC states that a child capable of forming his or her own views must be given the right to express those views freely in all matters concerning them, with the weight given in accordance with the age and maturity of the child. This contrasts 
with the Save the Children submission to the UN Summit on Social Development (1995) which highlighted the passive role generally assigned to children and the lack of recognition of children's potential to contribute to planning and decision making. A quarter of a century later, the voices of children and young people still often remain marginalised. Corsaro (2017) notes that adults most often view children as "future adults" (p.6) and in terms of what they will become rather than what they are in the present, with ongoing lives, needs and desires.

Conceptualisations of childhood are key as they determine how we engage with children and young people in research. Spears and Kofoed (2013) argue that the new sociology of childhood (James \& Prout, 1997; Corsaro, 2017) necessitates a valorisation of qualitative enquiry, centralising the position of youth voice, and elevating children and young people to agentic roles as co-researchers and co-generators of new knowledge. A mixed methods approach is thus proposed as a solution to the 'conundrum', allowing researchers and policy makers to understand prevalence, types of bullying, risk factors and predictors from quantitative data, but concurrently valuing the insights to be gained into lived experiences from, with and by young people themselves, who in recent years have embraced the advances in digital technology from the restrictions of 'wired' PC internet connectivity to the current ubiquity of 'wireless' $24 / 7$ online access via a growing range of devices including smart phones, tablets, PCs, laptops, games consoles and televisions (Slee, Campbell \& Spears, 2012).

Transgressing the binary positioning of the psychological and sociological traditions and their respective quantitative and qualitative emphases, a blending of approach is proposed which acknowledges the importance of statistical data (from large-scale surveys) but also youthcentred and youth-driven research. Within this participatory framework, research is co- 
designed and co-facilitated by children and young people, as agentive subjects, rather than passive objects of adult-initiated research. In terms of research into cyberbullying, Spears and Kofoed (2013) contend that qualitative enquiry into the lived experiences of children and young people has traditionally been little more than an "adjunct" (p.210) to quantitative methods, serving as a pre-cursor or follow-up to confirm more privileged survey data.

In advocating a participatory approach to research into cyberbullying among young people, several caveats must be noted. First, Hart's $(1992 ; 2008)$ ladder of participation is a useful reminder that the involvement of children and young people in research can often be little more than 'decorative' or 'tokenistic', masking traditional adult-led approaches and unequal partnerships between adults and children (e.g., a youth advisory group that meets once to confirm an adult-generated research design, or the use of children to ask adult-generated interview questions; Kellet, 2005). Second, it is evident that the elevation of young people to become "knowledge brokers" (Nutley, Walter \& Davies, 2007) and co-researchers requires commitment and investment of time and effort. And, third, while there is evidence of increasing research and policy engagement with young people, there is much less evidence of its impact on policy making and a suggestion that children and young people's voices are still being ignored (Badham, 2004; Tisdall \& Davis, 2004). It would appear that the voice of the child is therefore louder than in the past, but it is still barely audible and often no one is really listening.

\section{The Blurred Lives Project}

In response to this, the Blurred Lives project ${ }^{1}$ (2017-2019) was designed to redress the imbalance and to help give young people their voice back. The Blurred Lives project used a

\footnotetext{
${ }^{1}$ https://www.ou.nl/web/blurred-lives
} 
mixed method, co-participatory approach to explore the issue of cyberbullying amongst young people (aged 14-16) from areas of socio-economic disadvantage across five European countries (Northern Ireland, England, Germany, Italy and the Netherlands). The project aimed to involve young people by training and empowering them to use their voice as coresearchers to help tackle cyberbullying in their peer groups and schools. To enable this successfully, the Quality Circle approach (Cowie \& Sharp, 1992, 1994; Paul, 2014) and Sequential Focus Groups (Jacklin et al., 2016) were employed to 'climb' the ladder of participation (Hart, 1992; 2008), giving a voice to young people who are often marginalised because of their age and socio-economic status.

The focus in the Blurred Lives project on engaging young people from lower socio-economic backgrounds in co-participatory research on cyberbullying was highly original. Espinoza and Wright (2018) note that there is a need to extend cyberbullying research beyond its current predominant focus on the experiences of white, middle-class youth. Whilst there are several studies which have explored cyberbullying involvement among different marginalised and or diverse groups (those with disabilities: Kowalski \& Toth, 2018; minority ethnic youth: Barlett \& Wright, 2018), there are few with a focus on participatory approaches where young people can engage as co-researchers with adults. Others (Flewitt et al., 2018), have employed a participatory approach to highlight the challenges, responsibilities, and insecurities of the personal lives of disadvantaged children and young people, however, there have been no participatory studies to date which have focused specifically on the negative online experiences of young people from lower-socio economic backgrounds. The focus in the Blurred Lives project (2017-2019) of specifically engaging young people from lower socioeconomic backgrounds in co-participatory research on cyberbullying, is highly original and was designed to redress this imbalance in the cyberbullying literature and to provide young 
people with an opportunity to be empowered and have their voice heard. This article thus aims to evaluate the process, benefits and challenges of using co-participatory approaches to address cyberbullying with adolescent pupils from areas of socio-economic disadvantage.

\section{Methods}

The project consisted of two phases; in the first phase of the project 400-700 pupils were recruited from a range of schools in areas of socio-economic disadvantage in each of the five partner countries. They completed an online survey, exploring pupil access to the internet and any negative experiences they may have had as a result of using the internet, whether as victims, bystanders or perpetrators. The survey invited pupils to provide some background detail describing their demographics and internet use. This initial survey provided comments, experiences and suggestions for pupils to build upon during the second phase of the project, which used two co-participatory methods to create a safe space for young people to discuss their ideas and work together. One or two schools from each country were selected for the second phase in each country, with two classes from each country participating.

The first co-participatory method employed was the Sequential Focus Group (SFG). Jacklin et al. (2016) explain that SFGs are established over a period of time with a small membership who explore questions about an issue with each other and a group facilitator. These semistructured group interviews aim to bring people together to gain a deeper insight into the perspectives and lived experiences around the issue. In the Blurred Lives project, a small group of participants (Table 2) from each class volunteered to take part in the SFGs, one session before the Quality Circles and two afterwards. Each SFG had at least one participant who was nominated as a co-facilitator; their role encompassed asking questions with the researcher, encouraging others to answer questions and focusing the discussion. They were self-nominated, although some were encouraged by their teacher. They did not receive 
training for the role but were supported by discussing the plan for each session beforehand. The first SFG provided a platform to build upon the quantitative survey data and explore negative online experiences, while the latter SFGs provided 'peer-reviewed' feedback on the intellectual outputs and the Quality Circle approach in general. The facilitators subsequently acted upon these suggestions and made appropriate changes.

The second co-participatory method used was the Quality Circle (QC) approach. The primary aim of this method was to produce four intellectual outputs (resources) targeted towards pupils, parents/carers, teachers and social media providers that would raise awareness of the issue and enable them to help tackle cyberbullying in their context (the full range of completed resources in English, Dutch, German and Italian is freely accessible from the project website $)^{2}$. The approach was developed for business, to help employees enhance problem solving skills as a group. However, the QC approach has proved transferable to schools and subsequently Cowie and Sharp $(1992 ; 1994)$ developed a model for pupils to tackle bullying. The approach asks pupils to work together over an extended period during a series of researcher facilitated sessions to develop solutions to the issue of bullying. The structure provides opportunities for learning about bullying and develop thinking skills such as problem solving and collaboration.

The research team had agreed to facilitate 7 x 1-hour long QC sessions in each school, however, these differed in format, length and frequency across each country due to school logistics. For example, in Northern Ireland there were up to 11 weekly 30-minute QC sessions during the school day due to shorter class periods, whereas Germany and England

\footnotetext{
${ }^{2}$ https://www.ou.nl/web/blurred-lives/resources
} 
had fewer but longer sessions (up to 60 mins). A plan for each individual QC session was disseminated to each partner institution, however, the diversity in experiences proved challenging to control but does reflect the reality of education across multiple contexts.

During QC1, the project was introduced and pupils were divided into four groups by the teacher and facilitator, one for each of the intellectual outputs. The groups then played teambuilding activities to develop trust between peers. Rules for respect were created for the QC and each group nominated a scribe to provide feedback on their progress at the end of the session. The survey data were used throughout QC2 to QC5 for information and to stimulate ideas that were transferable into usable resources. During the final sessions, pupils had the opportunity to review the intellectual outputs (resources such as comic strips, posters, leaflets and presentations). Each group was also given the opportunity to present their resources to peers and/or the senior leadership team, making recommendations for how each target group could tackle cyberbullying more effectively. Some schools chose to organise a showcase event internally where pupils presented their resources whilst each project partner (university) organised a 'mulitplier event' to disseminate the project to educationalists, policy makers, pupils, parents and local media outlets. The Blurred Lives website link was shared widely to promote the resources; this website already has over 25,000 views from 4405 visitors across the globe.

After each QC session, facilitators (academic staff, postgraduate students and research assistants) completed a feedback form detailing pupil progress, engagement and any issues arising. This information was compiled by the research team in each country, providing insights into recurring themes, challenges and opportunities. 


\section{Participants}

Participants comprised 14-16-year-old pupils attending schools in areas of socio-economic disadvantage. Tables 1 and 2 present the number of participants in each QC and SFG.

$$
\text { [Insert Tables } 1 \text { and } 2 \text { here] }
$$

\section{Analysis of the Data}

The qualitative data relating to pupil experiences of the co-participatory approach was derived from two sources: the second SFG interviews and written evaluations (comprising eight questions ${ }^{3}$ ) distributed during the final QC session and completed by pupils. Once the data were collated centrally, a thematic analysis was carried out (Grbich, 1999; Braun \& Clark, 2006) by two independent coders, during which codes were generated, collated into themes, refined and verified. The data generated themes around developing skills, building self-esteem and the complexities of working with schools and young people. Written evaluations were completed by 183 of the 237 pupils who participated in the QCs across the five countries, representing a completion rate of $77 \%$.

\section{Results}

The results are presented in two parts; pupil data is presented first and summarises the feedback from the young people on their involvement in the project. This section exhibits comments from the pupil feedback forms and the SFGs, representing both positive and negative opinions. The second section exhibits reflections collected from the adult facilitators after each QC session. This data encompasses facilitator observations, and the benefits and challenges of working with schools.

\section{Feedback from pupils}

\footnotetext{
${ }^{3}$ See Appendix 1 for pupil evaluation questions
} 
From the thematic analysis of the pupil experiences (as expressed through the written evaluations and the SFG interviews) three key themes emerged: team work, learning about cyberbullying and building confidence. Overall, and in response to the first written evaluation question ('How have you felt the QC sessions have gone each week?') 96\% $(n=176)$ of the evaluation responses were positive (e.g. 'I think they went successful' [England], 'good and liked it very much' [Netherlands]). The other $4 \%(n=7)$ were negative comments which focused mostly on group dynamics (e.g. 'All right, but we didn't always agree' [Netherlands], 'Not everyone paid attention' [Italy]). Question 2 on the pupil feedback form ('Have you learned anything?') presented the most substantive answers to code along with data from the SFG transcripts. Other answers from the feedback forms did not provide sufficient detail (e.g. 'yes' or 'no' answers) to be included in any meaningful coding. Responses to Question 2 are summarised in Table 3.

\section{[Insert Table 3 here]}

The first key theme to emerge from the analysis of the pupil qualitative data was how the QC approach helped them to learn to work more effectively as part of a team or group. In the written evaluation, this was explored in particular through question 2 ('Have you learned anything?') where the most common responses related to team work skills (34 responses e.g. 'I have learned how to be better at group work' - Northern Ireland) and problem solving (5 responses e.g. 'problem solving and working with a great team' - England).

This theme was further explored in the SFGs where pupils were also very positive overall about the group learning experience:

'What skills have you learned?'

- 'That you can get to know people better and trust and work together'[Netherlands SFG]

- 'There should be more of these groups in which you can just talk to each other and with the teacher and with children you trust' [Netherlands SFG] 
'What do you think about doing this sort of group work in school generally? Would you like to see more of it?'

- 'More of it. We are taught to get on with it, sit with your head down, and not really interact. It works better when you are in a group' (Northern Ireland SFG)

The experience of working in a group was however less positive for a small minority of participants. A low number of written evaluation comments referred to groups where there was some evidence of disagreement ('a heated discussion' - England) or where there was poor cooperation among members ('not everyone paid attention' - Italy; 'some participants did not fully take part in the activities' - Northern Ireland). This was confirmed by a small number of focus group participants:

'I liked it a lot but there were too many people who didn't work at all and did not engage. I was telling them "Do this" but they did not do it.' [Italy SFG]

'I was the group leader. At the beginning it went very smoothly, but then it got stuck because they questioned work and doubted me.' [Germany SFG]

The second key theme to emerge was pupil learning about cyberbullying. This was further analysed into three subthemes: learning more about the nature and impact of cyberbullying; learning how to respond effectively to cyberbullying; and learning how to protect themselves online. Again, the comments in the written evaluations generally reflected those expressed in the SFGs.

In the written evaluations, in response to question 2 ('Have you learned anything?') a total of 12 young people referred specifically to their increased knowledge about the nature and impact of cyberbullying due to their participation in the QCs (e.g. 'I've learned how cyberbullying victims feel' - Italy). This was mirrored in several comments from the SFGs where pupils spoke of the benefits of the interactive approach over more didactic approaches: 
'It's more interactive. You can actually get involved instead of just sitting here...it's good because you get to look up things you would not really look up, like issues on cyberbullying and how it affects people.' (Northern Ireland SFG)

A further 11 young people reported in their written evaluations that they had learnt more about how to respond effectively to cyberbullying incidents involving themselves and/or their friends. This increase in their digital safety skills included many general comments ('I have learnt how to deal with a cyberbullying situation' - England) but also some more specific references to blocking, reporting abuse, and supporting their peers (e.g. 'I've learned that if a friend or a stranger needs help, I should be there for him' - Italy).

There were also 11 written evaluation comments by young people who commented on how they had learnt skills to be safer online and so help protect themselves from cyberbullying (e.g. 'I have learnt how to prevent it and who to talk to' - England; 'how to use social media safely' - Northern Ireland). This was confirmed by several comments in the focus groups. For instance, one pupil remarked that cyberbullying 'is increasing more and more, then you can better protect yourself or seek help' (Germany SFG).

The third theme to emerge from the pupil feedback was the growth in confidence from creating an original resource but also from communicating within the group setting and (for those who did so) presenting their work to a wider audience of peers or school leaders. This was reflected in a wide range of specific comments from the written evaluations where participants spoke highly of the final presentation session and their pride in their achievements:

'Best session? Why?'

'Yes, the last one, as we finally saw our work finished, and it turned out well and we're satisfied' [Italy] 
'I certainly liked it and I liked the presentation and I thought it was important' [Netherlands]

This sense of pride in their achievements and growth in confidence also featured in some of the SFG interviews, accompanied by satisfaction that the materials produced would be used beyond their immediate school context:

'What were the good aspects?'

'That the materials are actually going to be used' [Netherlands SFG]

There was also a clear sense that, while initially disconcerting to be working outside their friendship groups, this was (for most) ultimately empowering, giving a voice to everyone in the group:

'You have got people with big personalities and a lot of people who were shy. It was good to sort of have a mixture of both, where you have opinions and you are actually able to get opinions out of people who would not usually voice their opinion.' [Northern Ireland SFG]

However, there were young people who did not enjoy the QC experience. A total of 23 responses $(13 \%)$ to the written evaluation said that they had not learnt anything from their participation and there were a small number of negative comments across all partner countries from young people who didn't enjoy working in groups. In terms of the level of coparticipation, several young people in different countries expressed their frustration that they did not have more autonomy to decide on the particular resources, as these had been predetermined by the research team when submitting the funding application:

'There were really great ideas but we couldn't develop them (such as a video). We had to conform to the requests you made. In the end the work was fine but not what it could have been if we had followed our own idea.' [Italy SFG] 
Similar sentiments were expressed during the initial QC session by some of the pupils in Northern Ireland and Germany who each chose to work on outputs other than the comics which had been chosen by the project team.

\section{Feedback from facilitators}

The thematic analysis of the facilitator feedback highlighted three key themes that impacted upon the project. These data were gathered and collated using facilitator feedback forms and written report summaries. Overall, the facilitators agreed that using the QC approach in this project was generally a positive experience, however, it presented challenges in each country.

The first key theme highlighted was the level of support each school provided during the project. This manifested in varying degrees of time investment and engagement from teachers and senior leadership along with support in timetabling the sessions and recruiting pupils. For example, one German facilitator stated that, 'while session scheduling was trouble-free in School 1, the start of the project was continuously delayed by our second school due to internal issues (starting with a five-month delay).' Facilitators in Northern Ireland faced a similar situation whereby 'on at least three occasions, the QC sessions were cancelled (in School 1) with little or no prior notice by the year head who used this period for special year assemblies.' This delayed the second phase of the project causing long gaps between sessions and frustration for facilitators. School buy-in was thus an important factor in the success of the project and set the tone for implementation; gaining this buy-in was more straightforward with schools where researchers had existing professional contacts.

The level of support provided by teachers also impacted on the QC experience. In England, 'no teachers were present at the QC sessions, but the research team recruited a pool of highly 
qualified helpers to assist, ideally one helper per resource group with a lead facilitator overseeing the general running and timing.' This enhanced the productivity of the sessions as the group could focus more diligently on the task with a consistent point of contact. Although one might assume that not having the class teacher present would cause more issues, this did not seem to be the case in England. By contrast, in the first school in Northern Ireland, the teacher that the project had been arranged with was not present in the classroom, and instead a substitute teacher supervised the class. This presented issues as the pupils did not have a rapport with the teacher who in turn did not know the needs of the pupils ultimately impacting on the level of support available to pupils. Comparatively, the teacher in the School 2 was heavily involved in the project throughout, facilitating the pupils and encouraging their progress. Although teacher involvement was not a prerequisite for the project, some researchers found the support useful, particularly when seeking the support of senior leadership.

The second emerging theme was the level of pupil engagement in the QC sessions. All partner institutions reported 'high variability' in pupil engagement. For example, in Italy and Germany, the facilitators reported that 'many groups had at least one outsider' who rarely took part in any activities 'unless directly addressed by a facilitator or student.' This theme was also reflected in reports from the Netherlands where one of the QC participants was absent for the first three sessions and so missed out on making decisions during the resource development stage. The facilitator observed that this pupil was consequently much less involved in discussions and the others working together in the group found the process of involving her onerous and time consuming. The Italian facilitators agreed that groups who established common goals and a climate of co-operation during the first sessions 'were often able to keep a higher level of engagement among their participants.' In Germany, the 
facilitators observed that pupils were distracted and lacked concentration, particularly in the afternoon sessions organised in one of the schools. This disruption reduced when the groups started to work on their resources in different areas of the school, mitigating potential distractions. However, this behaviour contrasts with that of other Dutch pupils who, in some cases, 'went well beyond what was required of them, for example, organising spontaneous group meetings after school to further discuss the project topics to work on their respective outputs.' For facilitators in England, pupil engagement varied between schools due to different learning and teaching cultures. One facilitator observed that in School 1, the QC approach 'required the students to be in charge of creating each of the resources and their lack of experience and exposure to this style of working was apparent.' These pupils struggled with this dynamic, often leading to a lack of participation and engagement, despite the best efforts of the facilitators. However, in the second school, the facilitator reported that 'although the students were more challenging in their behaviour and attendance, they appeared to be more at ease with the student-led aspect of this approach.' This was reflected through positive group interactions and experiences. Facilitators from England, the Netherlands and Northern Ireland felt that pupil engagement was related to pupil year group (age), maturity and motivation.

The third theme to emerge from the facilitator reflections was appropriate scaffolding. All evaluations raised the specific challenge of 'striking the balance between encouraging independent pupil led output and providing scaffolded support.' The Italian facilitators described the tension 'between the aim of prioritising youth voice, and the need to carry out a project with pre-defined aims, focus and expected outputs.' This became especially apparent during the QCs where a tension emerged between enabling pupil voice and creating acceptable resources for distribution. This was exacerbated by the pre-defined outputs 
decided during the funding application process that did not always correspond with subsequent pupil preference. For example, pupils in Northern Ireland did not want to make a comic book resource as they felt that this medium would not appeal to their peers. There were similar challenges in Germany and Italy, where the facilitators and pupils compromised in using different media or rearranging and creating multiple outputs to satisfy the needs of both parties. Conversely, pupils from the Netherlands were very enthusiastic to produce a comic strip resource, even though the facilitator discussed the additional support and instruction needed to develop a storyline and translate it into frames with illustrations.

German and Italian facilitators commented that pupils generally struggled with the selfregulation required to participate fully, however, they reflected that this may be due to the particular educational needs and abilities of their respective groups. In alignment with the Northern Ireland facilitator's feedback, they felt that the addition of more personnel resource would have been beneficial, particularly with pupils with lower academic ability requiring additional support. However, facilitators from both England and the Netherlands felt that the support they provided (two facilitators in the Netherlands and four facilitators in England) was sufficient.

\section{Discussion}

The current paper aimed to evaluate the usefulness of the QC approach in combination with SFGs to discuss and address cyberbullying by giving young people a role as co-researchers. To our knowledge, this is the first study that has used the QC approach among this population on a large scale across five countries. The results provide new insights into the process of using a co-participatory approach and the impact it can have on adolescent development and provides important suggestions for effectively implementing this approach. 
The results suggest that the co-participatory approach has a positive impact on encouraging young people to better understand and systematically challenge cyberbullying. The student evaluation forms and SFGs highlighted three important themes for personal development: first, learning about the nature and impact of cyberbullying and how to respond and protect oneself online; second, learning to work more effectively as part of a group; and, third, developing increased confidence in creating behavioural change interventions and presenting these to peers/stakeholders. Following an earlier example with younger secondary pupils in England alone (Paul et al., 2010; Paul et al., 2012) the young people in this Europe-wide project participated in a series of QC workshops, where they learned how to analyse problems, identify key issues, and generate pupil-led solutions. Paul et al. (2012, p.9) had noted briefly that the pupil evaluation of their QC work was 'generally positive' with pupils reporting QCs as 'enjoyable and a good use of learning time.' Pupils had been enthusiastic, demonstrating an 'ability to take responsibility for addressing problems in schools' (p.9). The evaluation of the Blurred Lives project was however much more comprehensive and nuanced, and highlighted generally (but not exclusively) positive pupil feedback about the co-participatory approach undertaken, a sense of empowerment, engagement and agency among many of the pupils, and genuine learning about cyberbullying in terms of incidence, impact and how best to protect themselves and their friends online.

Other valuable insights gained concern the challenges experienced in facilitating a coparticipatory approach among this population in particular. Feedback from the QC facilitators elicited three important themes: first, the amount of scaffolding during QC sessions; second, the level of individual engagement by the young people; and, third, the level of support and commitment by school staff. 
In terms of scaffolding, the results show that it was a challenge to find the right balance between encouraging pupil agency, self-regulation, independence and creativity on the one hand, and on the other hand providing adequate scaffolding, guidance, encouragement, and practical support to produce high-quality outputs. Indeed, it quickly became clear that direction and guidance were undoubtedly required to ensure a final output which both looked good and contained accurate information and helpful advice. This project differed from earlier QC work by Paul et al. (2012) on account of the greater pressure to achieve a final product (to satisfy the project funder and to make the final resources publicly available). On the one hand, this served as a motivation for the pupils to work hard, but on the other perhaps encouraged facilitators to play a more directive role than in earlier studies.

Two key strategies are recommended to help achieve an appropriate balance: first, it is important to establish a clear plan for each QC session, which should include a clear goal, specific tasks and checklists to help pupils understand what they need to do each week, including the time required to achieve this. This is required not just on a whole-group level but on a subgroup level too:

"Our experience was that these students found it very difficult to take leadership in their work, managing time, and planning steps to undertake. Therefore, students were structurally guided and tasks were assigned, while still letting them create their own ideas" (Netherlands)

Second, it is useful to provide exemplars of the final outputs. Since many of the participating pupils were not used to working independently on a creative task, it is recommended that QC facilitators bring along sample materials (e.g., leaflets, flyers) emphasising that these are only examples and the pupils' own creations can look very different. 
Despite such strategies, a minority of pupils still struggled to commit wholeheartedly to a project whose focus, main outputs, and group membership had been pre-determined by the research team, and the resulting tension became apparent in these pupils' lack of engagement:

'This might also have played a role in undermining the engagement of pupils who felt that the project's aims were not aligned with their own problems and interests. For instance, one of the students referred to the facilitator to be living in a foster care community and to experience serious problems of physical bullying; he explained that cyberbullying was not a real problem to him' (Italy)

This is a legitimate criticism of the approach taken in this particular funded project. It is therefore recommended that researchers/facilitators engage with the young people at an earlier stage, for instance through focus groups, to gain agreement on the focus of the QC work and the format or medium of any proposed outputs.

Facilitators also noted that, in line with previous studies (Flewitt et al., 2018) there were particular challenges in adopting a participatory approach with a sample of young people from socially disadvantaged backgrounds and with higher than average rates of special and additional educational needs. This necessitated a higher than normal ratio of adult facilitators to pupil participants to support their engagement, learning and continued focus.

In terms of school involvement, while in the majority of schools, the school principal and at least one other person were highly committed to supporting the Blurred Lives Project, in a few cases implementation became challenging and significantly impacted on the running of the QCs. For others hoping to adopt this approach in the future, it is recommended that they enlist support from the outset from the school principal and at least one other committed staff member; that sufficient time is scheduled (e.g., optimally around 7 hour-long weekly sessions or fewer longer sessions); that practical requirements are addressed in advance (e.g., finding a 
suitable room, organising laptops); that other colleagues are briefed about the QC activities and its potential to improve class climate; and that a celebratory presentation is facilitated for the pupils to showcase their work to peers and senior staff. While this requires additional effort at the planning stage, it is likely to ensure the smoother running of the QCs.

'Although each of these seem like minor details, the combination of limited
time, supervision and resourcing were definitely contributory factors to the
success of the Quality Circle experience, the learning gained and the
quality of the resources produced' (Northern Ireland)

\section{Limitations}

The results of this study should be interpreted in light of several limitations. Some important challenges have already been discussed. First, although the QC sequence and frequency were structurally planned, it proved practically impossible to follow the exact programme across each country and even between schools in the same country. Each respective project team had to negotiate access to classes (often benefiting from existing contacts), and were often not at liberty to determine how many sessions could be facilitated, of what length, over how many weeks, and in which classroom. In the best instances, project teams had flexible, wellequipped classrooms and at least an hour each week for the QCs; in the worst cases, allocated classrooms were cramped, IT equipment was slow, and sessions were cancelled without notice. This, and an inevitable variation among pupil participants (in terms of ability and engagement) and facilitators (in terms of degrees of support required and provided), inevitably meant that the fidelity of the QC approach across the five countries was not guaranteed. In addition, while each of the schools were in areas of social disadvantage, pupil background was not examined at an individual level, so it is likely that there was variation within and between QCs in terms of pupil background. That said, the research team felt that these limitations had only a minor impact on the expected outputs. 


\section{Conclusion}

Notwithstanding the challenges and limitations outlined above, the current five-country study suggests that Quality Circles represent a valuable co-participatory approach to help young people better understand and address cyberbullying, facilitating youth voice and (in this case) leading to useful intervention materials such as the Comic Bookfor Pupils, Resources for Teachers, Guidance for Parents/Carers and Recommendations for Social Networking Providers. Quality Circles thus have the potential to valorise young people as agentic coresearchers and co-generators of new knowledge (Spears \& Kofoed, 2013). In addition to gaining knowledge about cyberbullying and how to protect themselves and their peers online, the QC approach thus affords pupils the opportunity to develop socioemotional (e.g., team work, self-regulation) and problem-solving skills. Far from being 'decorative' or 'tokenistic' (Hart, 2008), Quality Circles offer a meaningful opportunity to facilitate youth voice as they learn how to keep themselves and their peers safe online. From the experience of the Blurred Lives project, it can be concluded that the success of the Quality Circle approach among disadvantaged pupils is moderated by the level of school commitment, the number of trained adult facilitators, the extent of planning and preparation, and the extent to which the spirit of co-participation is honoured by giving the young people the opportunity to make meaningful decisions from the outset and throughout the entire process.

\section{Acknowledgements}

With thanks to all participating staff and pupils, project team members and additional QC facilitators across all five partner countries (listed below by country): England: Emma King, Simone Paul, Susanne Robinson, Binbin Gu Germany: Annegret Roschlau, Amrita Choudhry, Maria Stoykova, Madita Siddique Italy: Laura Menabò, Felicia Roga, Luana Fusaro, Sandra Maria Elena Nicoletti, Margherita Baldi, Carla Salvatore

Netherlands: Lizzy van der Linden 


\section{Conflicts of interest}

Dr Barbara Spears was an advisor to the Blurred Lives project; she is an editor of this special issue.

\section{Funding}

This work was supported by Erasmus+ under Key Action 2: Strategic Partnerships for School Education (Project Code 2017-1-UK01-KA201-036554)

\section{References}

Alderson, P. (2000). Children as researchers. In Research with Children. P. Christensen \& A. James (eds.). London: Falmer Press. pp. 241-257.

Badham, B. (2004). Participation - for a change: Disabled young people lead the way. Children and Society, 18, 143-154.

Barlett, C. P., \& Wright, M. F. (2018). Longitudinal relations among cyber, physical, and relational bullying and victimization: Comparing majority and minority ethnic youth. Journal of Child \& Adolescent Trauma, 11(1), 49-59.

Braun, V. \& Clark, V. (2006). Using thematic analysis in psychology. Qualitative Research in Psychology, 3 (2), 77-101.

Corsaro, W. (2017). The Sociology of Childhood ( $5^{\text {th }}$ edition). London: Sage.

Costabile, A. \& Spears, B. (2012). The Impact of Technology on Relationships in Educational Settings. London: David Fulton.

Cowie, H. (2013). Cyberbullying and its impact on young people's emotional health and wellbeing. Psychiatrist. 37. 167-170. 10.1192/pb.bp.112.040840.

Cowie, H. \& Sharp, S. (1992). Students themselves tackle the problem of bullying. Pastoral Care in Education, 10, 31-37.

Cowie, H. \& Sharp, S. (1994). Tackling bullying through the curriculum. In P.K. Smith \& S. Sharp (Eds.), School Bullying: Insights and Perspectives. London: Routledge.

Ditch the Label (2019) The Annual Bullying Survey 2019. Available at: https://www.ditchthelabel.org/research-papers/the-annual-bullying-survey-2019/ (accessed 15 March 2020)

Espinoza, G. \& Wright, M. (2018). Cyberbullying experiences among marginalised youth: What do we know and where do we go next? Journal of Child \& Adolescent Trauma, $11,1-5$.

Flewitt, R., Jones, P., Potter, J., Domingo, M., Collins, P., Munday, E. \& Stenning, K. (2018). 'I enjoyed it because ... you could do whatever you wanted and be creative': three principles for participatory research and pedagogy, International Journal of Research \& Method in Education, 41(4), 372-386.

Grbich, C. (1999). Qualitative Research in Health: an Introduction. London: Sage.

Hart, R. (1992). Children's participation: from tokenism to citizenship. UNICEF Innocenti Essays, No.4 Florence, Italy: International Child Development Centre of UNICEF.

Hart, R. (2008). Stepping back from the ladder: reflection on a model of participatory work with children. In A. Reid, B.B. Jensen, J. Nikel \& V. Simovska (Eds.), Participation and Learning: Perspectives on education and the environment, health and sustainability (pp.19-31). Dordrecht: Springer. 
Jacklin, K., Ly, A., Calam, B., Green, M., Walker, L., \& Crowshoe, L. (2016). An innovative sequential focus group method for investigating diabetes care experiences with indigenous peoples in Canada. International Journal of Qualitative Methods, 15(1), 112.

James, A. \& Prout, A. (1997). Constructing and Reconstructing Childhood (2nd edn). Basingstoke: Falmer Press.

James, A., Jenks, C. \& Prout, A. (1998). Theorizing Childhood. Cambridge: Polity Press.

John, A., Glendenning, A.C., Marchant, A., Montgomery, P., Stewart, A., Wood, S., Lloyd, K., Hawton, K. (2018) Self-harm, suicidal behaviours, and cyberbullying in children and young people: Systematic review. Journal of Medical Internet Research, 20(4), 129-140.

Kellet, M. (2005). Children as active researchers: a new research paradigm for the 21st century? ESRC National Centre for Research Methods. Available at: http://eprints.ncrm.ac.uk/87/1/MethodsReviewPaperNCRM-003.pdf (Accessed 31 January 2020).

Kofoed, J. \& Staksrud, E. (2018). 'We always torment different people, so by definition, we are no bullies': The problem of definition in cyberbullying research. New Media \& Society, 21(4), 1006-1020.

Kowalski, R.M. \& Toth, A.J. (2018). Cyberbullying among youth with and without disabilities. Journal of Child \& Adolescent Trauma, 11(1), 7-15.

Kowalski, R. M., Giumetti, G. W., Schroeder, A. N., \& Lattanner, M. R. (2014). Bullying in the digital age: A critical review and meta-analysis of cyberbullying research among youth. Psychological Bulletin, 140, 1073-1137.

Låftman , S. B., Modin, B. \& Östberg, V. (2013). Cyberbullying and subjective health: A large-scale study of students in Stockholm, Sweden. Children and Youth Services Review, 35(1), 112-119.

Livingstone, S. \& Helsper, E. (2010). Balancing opportunities and risks in teenagers's use of the internet: The role of online skills and internet self-efficacy. New Media \& Society, 12(2), 309-329.

Nutley, S.M., Walter, I., \& Davies, H.T.O. (2007). Using Evidence: how research can inform public services. Bristol: The Policy Press.

Olweus, D. (1994) Annotation-Bullying at school: Basic facts and effects of a school based intervention program. Journal of Child Psychology Psychiatry and Allied Disciplines, 35(7), 1171-1190.

Park, S., Nab, E. Y. \& Kim, E. (2014). The relationship between online activities, netiquette and cyberbullying. Children and Youth Services Review, 42, 74-81.

Paul, S., Smith, P.K. \& Blumberg, H.H. (2010). Addressing cyberbullying in school using the Quality Circle Approach. Australian Journal of Guidance and Counselling, 20, 2, 157-168.

Paul, S., Smith, P.K. \& Blumberg, H.H. (2012). Revisiting cyberbullying in schools using the Quality Circle Approach. School Psychology International, 33(5), 1-13.

Paul, S. (2014). Beyond Bullying: researching student perspectives. London: Routledge.

Save the Children (1995). Towards a children's agenda: New challenges for social development. London: Save the Children. 
Schubotz, D. (2020). Participatory Research: Why and How to Involve People in Research. London: Sage.

Schultze-Krumbholz, A. \& Scheithauer, H. (2015). Cyberbullying. In T. P. Gullotta, M. Evans \& R. Plant (Eds.), The handbook of adolescent behavioral problems. Evidencebased approaches to prevention and treatment (2nd ed.). New York: Springer.

Slee, P.T., Campbell, M., \& Spears, B. (2012). Child, adolescent and family development (3rd edition). Cambridge: Cambridge University Press.

Smith, P. K., Mahdavi, J., Carvalho, M., Fisher, S., Russell, S. \& Tippett, N. (2008). Cyberbullying: its nature and impact in secondary school pupils. Journal of Child Psychology and Psychiatry, 49(4), 376-385. Available at: https://onlinelibrary.wiley.com/doi/full/10.1111/j.1469-7610.2007.01846.x (Accessed 31 January 2020).

Spears, B. \& Kofoed, J. (2013). Transgressing research binaries: youth as knowledge brokers in cyberbullying research. In P.K. Smith \& G. Steffgen (Eds.), Cyberbullying through the new media. London: Psychology Press.

Tisdall, E.K.M. \& Davis, J. (2004). Making a difference? Bringing children and young people's views into policy-making. Children and Society, 18 (2), 131-141.

UNICEF. (1989). The UN Convention on the Rights of the Child. Available at: https://www.unicef.org.uk/what-we-do/un-convention-child-rights/ (Accessed 31 January 2020).

United Nations (2001). General Comment No.1: The Aims of Education (article 29).

Available at:

https://www.ohchr.org/EN/Issues/Education/Training/Compilation/Pages/a)GeneralC ommentNo1TheAimsofEducation(article29)(2001).aspx (Accessed 31 January 2020).

\section{Appendix 1}

\section{Quality Circle pupil evaluation questions}

1. How have you felt the Quality Circle sessions have gone each week?

2. Have you learned anything?

3. Have you enjoyed working in your groups? - Best sessions? Why?

4. Did you have any difficult moments in your group?

5. Could you have worked differently with one another? Please explain

6. Did you understand your task each week? Was it clearly described?

7. What do think about the Quality Circle approach?

8. Any other comment?

Table 1: Quality Circle Participants

\begin{tabular}{|c|c|c|c|c|c|}
\hline Country & School & Number of Participants & Age & Male & Female \\
\hline England & School 1 & 31 & $13-14$ & 17 & 14 \\
\hline & School 2 & 28 & $14-15$ & 14 & 14 \\
\hline Germany & School 1 & 21 & $14-16$ & 15 & 6 \\
\hline & School 2 & 24 & $14-16$ & 16 & 8 \\
\hline
\end{tabular}




\begin{tabular}{|c|c|c|c|c|c|}
\hline Italy & School 1 & 24 & $14-16$ & 24 & 0 \\
\hline & School 2 & 26 & $14-16$ & 8 & 18 \\
\hline & School 3 & 16 & $14-16$ & 10 & 6 \\
\hline Northern Ireland & School 1 & 21 & $15-16$ & 12 & 9 \\
\hline & School 2 & 19 & $14-15$ & 9 & 10 \\
\hline The Netherlands & School 1; group 1 & 12 & $14-15$ & 3 & 9 \\
\hline & School 1; group 2 & 15 & 14 & 6 & 9 \\
\hline
\end{tabular}

Table 2: Sequential Focus Group Participants

\begin{tabular}{|c|c|c|c|c|c|}
\hline Country & School & Number of Participants & Age & Male & Female \\
\hline England & School 1 & 16 & $13-14$ & 8 & 8 \\
\hline & School 2 & 16 & $14-15$ & 8 & 8 \\
\hline Germany & School 1 & 8 & $14-16$ & 1 & 7 \\
\hline & School 2; group 1 & 12 & $14-16$ & 4 & 8 \\
\hline & School 2; group 2 & 12 & & 4 & 8 \\
\hline & School 1 & 8 & $14-16$ & 8 & 0 \\
\hline & School 2 & 8 & $14-16$ & 4 & 4 \\
\hline & School 3 & N/A & $14-16$ & N/A & N/A \\
\hline Northern Ireland & School 1 & 5 & $15-16$ & 2 & 3 \\
\hline & School 2 & 7 & $14-15$ & 3 & 4 \\
\hline The Netherlands & School 1; group 1 & 8 & $14-15$ & 3 & 5 \\
\hline & School 1; group 2 & 8 & 14 & 3 & 5 \\
\hline
\end{tabular}

Table 3: 'Have you learned anything?' (Question 2 from pupil evaluation forms)

\begin{tabular}{|l|c|c|}
\hline Type of pupil learning & Number & Percentage \\
\hline Team work/co-operation & 34 & $21.3 \%$ \\
\hline Presenting to others/communication/ using PowerPoint & 15 & $9.4 \%$ \\
\hline General impact of cyberbullying & 12 & $7.5 \%$ \\
\hline How to protect myself online/block/ defend/stay safe & 11 & $6.9 \%$ \\
\hline How to respond to cyberbullying (e.g. helping friends, reporting) & 11 & $6.9 \%$ \\
\hline Problem solving & 5 & $3.1 \%$ \\
\hline Other & 4 & $2.5 \%$ \\
\hline Research skills & 3 & $1.9 \%$ \\
\hline No learning & 23 & $12.5 \%$ \\
\hline
\end{tabular}

